\title{
Event-Driven Management of Economics and the Exit of Economics from Stagnation
}

\author{
Eugene Solozhentsev \\ 1) Institute of Entrepreneurship Technologies \\ St. Petersburg State University of Aerospace Instrumentation \\ 2) Institute of Problems of Mechanical Engineering of RAS \\ Saint-Petersburg, Russia, \\ esokar@gmail.com
}

\begin{abstract}
The work describes the developed cortege and mathematical model for managing the quality of development and exit of the system from stagnation. The scientific problem of economics development is formulated on the basis of artificial intelligence, algebra of logic and logical-probabilistic calculus.
\end{abstract}

Keywords - Development, stagnation, model, system, economics, event-driven management, cortege, quality criterion.

\section{INTRODUCTION}

Academician A. G. Aganbegyan indicate that the way out of stagnation is the most difficult process of the country's economics crisis [1]. The country's economics has been stagnating for over 20 years. Scientistseconomists offer different approaches based on the successful experience of other countries. But agreement and a single solution are no found, and stagnation continues.

The theory of managing economics and the state is unsatisfactory. She has no fundamental achievements. In recent years, Nobel Prizes in economics have been awarded to papers that have not made a significant contribution in economics science. Management in the modern economics is carried out without mathematical methods and models, on the basis of adjustment and regulation, "by concepts", "manual control", "give more money", advice, promises and measures. Management of economics and the state is carried out exclusively "from above" which leads to corruption. We can say: "Faith served us as a shield for the mind. But then we need the science of granite". This work is devoted to solving this problem.
Event-driven management of economics is proposed, focused on improving the quality of economics, the state and human life [2]. Event-driven management is the artificial intelligence technique. Event-driven management is based on the algebra of logic and logicalprobabilistic calculus (LP-calculus).

The scientific novelty of the work is as follows:

- The definition of Boolean event-propositions has been expanded and the measure of invalidation is defined as the probability of failure. We use estimates of the probabilities of events on based of invalidity, non-numerical inaccurate and incomplete expert information [3], identifying a logical-probabilistic model of failure on statistical data [4].

- Developed the cortege to describe the system of event-driven management of the quality of economics. Created a unified set of tools for managing the quality of economics and the state in the digital economics.

- A mathematical model for managing the quality of development and exit of a economics from stagnation has been developed.

\section{EVENT-DRIVEN MANAGEMENT OF THE ECONOMICS QUALITY}

Event-driven management is a method of artificial intelligence [5]. Management objects are structurally complex systems and processes in economics. Eventdriven management based on logic algebra and LPcalculus. The event-driven management of real systems and processes is considered. Management components are subjects (who solves the problem), objects (what tasks are being solved) and infrastructure. In event-driven 
management, arithmetic and logical calculations have great complexity are performed. Therefore, a computer and special software are used. Event-driven management is carried out any L-complexity of the system.

The formulation of a new scientific direction required a transition to a qualitatively new level of outlook and the introduction of new knowledge and new tasks for managing the quality of economics and the state. Proposed event-driven management of the quality of economics and the state "from above" and "from below" based on artificial intelligence.

In event-driven management, the management of the quality of human life considered for the first time. The quality of a person's life is presented in the form of Laddition of the quality of his life processes. Quality management of life processes (treatment, education, decision-making) and the construction of appropriate models is carried out with the participation of the person himself. Models give results for management from below, which are at the same time feedback for management from above.

Event-driven management of the quality of the state and economics (systems and processes) is based on events. We consider invalid events, meaning the deviation of the system parameters from the requirements and norms. Different systems and processes can have common triggering events and this ensures their connection. LP-risk models of different systems can simply be logically combined into one common LP-risk model, on which to solve the problems of assessment, analysis, forecasting and management of the state and development of a large system. The characteristics of event-driven management of quality are as follows:

- The event-driven management system is described by the proposed cortege.

- Event-driven management of systems and processes is carried out on the LP-model according to the quality criterion.

- Problems are solved for any complexity of the logical model of the system.

- Event-driven management allows to obtain quantitative estimates of the quality and contributions of initiating events to the values of the criterion.

- Operations of logical-probabilistic calculus are performed with both logical variables and logical functions.

- The logical functions of risk (failure) have neither coefficients nor degrees.

- The dynamism of LP-models of safety and quality is ensured by correcting the probabilities of initiating events in response to signaling events.

- The dependence and connection of various systems (models) ensures the correct accounting of repeated events in the systems that are included in a large system.

\section{THE CORTEGE OF THE SYSTEM OF EVENT-DRIVEN MANAGEMENT OF THE QUALITY OF ECONOMICS}

The cortege of the quality management system of economics and the state includes the following components:

$-S=\left\{S_{1}, S_{2}, S_{3}, S_{4}, S_{5}\right\}-$ Objects, Criteria, Knowledge, Tasks, Provisions;

$-S_{1}=\left\{S_{31}, S_{32}, S_{33}, S_{34}, S_{35}, S_{36}, S_{37}, S_{38}, S_{39}\right\}-$ New management objects: Ministries, Social-economics systems, Enterprises and companies, Safe living space, Quality of human life;

$-S_{2}=\left\{S_{21}, S_{22}, S_{23}\right\}-$ Criteria for quality, safety, efficiency;

$-S_{3}=\left\{S_{31}, S_{32}, S_{33}, S_{34}, S_{35}, S_{36}, S_{37}, S_{38}, S_{39}\right\}-$ Subjects (who decides): President, State Duma, Federation Council, Government, Banks, Business, Scientists, Public Opinion, Person;

$-S_{4}=\left\{S_{41}, S_{42}, S_{43}, S_{44}, S_{45}, S_{46}, S_{47}, S_{48}, S_{49}\right\}-$ New knowledge: Methodological foundations, New Boolean events-propositions, LP-models, Public opinion, Special Software, Technology, Probabilities of Events, Continuing Education Course;

$-S_{5}=\left\{S_{51}, \ldots S_{5 i}, \ldots S_{5 n}\right\}-$ New tasks;

$-S_{6}=\left\{S_{61}, S_{62}\right\}-$ Provisions: LP-calculus, Unified set of tools for the Digital Economics.

Let write components of the cortege in more details:

$-S_{15}=\left\{S_{151}, S_{152}, S_{153}, \ldots\right\}-$ Quality of human life: processes of treatment, learning, decision-making;

$-S_{43}=\left\{S_{431}, S_{432}, S_{433}, \ldots\right\}-$ New Boolean eventspropositions in management: about the failure of subjects, about the failure of objects, about signaling events in economics and politics, about invalidity, about conceptual forecasting, about danger and legitimacy, about groups of incompatible events;

$-S_{44}=\left\{S_{441}, S_{442}, S_{443}, \ldots\right\}-$ New risk models: structural and logical, according to statistical data, hybrid, invalid, conceptual, indicative, development management, quality of management systems, living space, human life, exit from stagnation;

$-S_{45}=\left\{S_{451}, S_{452}\right\}-$ Public opinion: Management "from above", Management "from below";

$-S_{46}=\left\{S_{461}, S_{462}\right\}-$ Special software: Arbiter, Expa;

$-S_{47}=\left\{S_{471}, S_{472}, S_{473}, S_{474}\right\}-$ Risk technologies: procedures for constructing risk LP-models, model analysis, forecasting on a risk model, risk management;

$-S_{48}=\left\{S_{481}, S_{482}, S_{483}\right\}-$ Estimation of the probabilities of events by: the invalidity of indicators, identification of the risk model using statistics, nonnumerical, inaccurate and incomplete expert information;

$-S_{49}=\left\{S_{491}, S_{492}\right\}-$ Additional education course: lectures and laboratory work. 
In [6 - 10], the components of the cortege of the quality management system of economics and the state, new knowledge and new tasks to be solved are considered in detail. For the quality management system of economics and a government of a region and an enterprise, a similar map should be used with components and tasks of the appropriate level.

\section{MANAGEMENT OF THE DEVELOPMENT OF A SYSTEM TO EXIT FROM STAGNATION}

The list of new effective problems in economics (see the cortege) is as follows [2,11]:

1. Modeling, analysis and quality management of one and several logically integrated systems.

2. Taking into account the effect of repeated events on the quality assessment of the integrated system.

3. Analysis of different outcomes of quality management of subsystems in a complex system.

4. Monitoring and management of the bank lending process.

5. Counteracting bribes and corruption.

6. Safety management of the living space.

7. Managing the quality of human life (processes of treatment, education, decision making).

8. Event-driven management of the economy's exit from stagnation, etc.

These tasks are not formulated either in the plans of the government of the country, or in the national projects "Digital Economy" and "Artificial Intelligence", or in the priority fundamental scientific research areas of the Russian Federation and the Russian Academy of Sciences.

The formation of a new scientific direction in the management of the quality of economics and the state required a transition to a new level of worldview and the introduction of new knowledge and new tasks.

Below we consider in detail only one new important task of economics "Event-driven management of the system to get out from position of stagnation".

Stagnation (Latin stagnatio - immobility, from stagnum - stagnant water) is a state of the economics characterized by stagnation of production and trade for a long period of time. Stagnation accompanied by an increase in the number of unemployed, a decline in wages and living standards of the population. It is expressed in zero or insignificant growth rates, unchanged structure of economics, its immunity to innovations, scientific and technological progress [1].

Stagnation occurs during the transition from a command-administrative to a mixed economics and is a consequence of the economic mistakes of governments, ignorance of economic laws. In particular, in economics of the post-Soviet states in the 1990s, stagnation manifested itself in a sharp decline in production and investment activity, physical destruction of productive forces, primarily in the scientific, technical and intellectual potential of society, as well as a devaluation of motivational incentives for productive work. The crisis has engulfed the sphere of finance and money circulation. The crisis of non-payments was especially acute. Due to the lack of competitive goods, the post-Soviet countries were unable to quickly integrate into the international market system. At the same time, the national economic complex of the country and economic ties between industries were destroyed.

In fact, the author first developed a stagnation management system in 1982 in his doctoral dissertation (Institute of Cybernetics, Kiev). In the work "Fundamentals of building systems for automated debugging of complex technical systems", the author studied systems of debugging tests of free-piston engines, which were destroyed within up to $1 \mathrm{~min}$ after starting. To establish the factors that led to the destruction, it was necessary to have time to measure several parameters. For this, the test bench was equipped with artificial systems in order to implement a significantly less intense thermal and dynamic mode of starting and operating the engine. So it was possible to measure the parameters and build a model of the heat-stressed state of the engine. At the subsequent stages of testing, artificial systems at the stand were gradually removed.

Engineering test management is the management of stagnation in economics. Fig. 1 "Stagnation management scheme" taken from the thesis. Economists who are solely concerned with profits, not the quality of life of the population, and without knowing the algebra of logic, have not noticed the widely published results. Economic science has become smaller in the country - there are many institutes, research centers, experts and consultants. The problem of managing the quality of economics and the state is complex at the intersection of technology, economics, management and artificial intelligence. Complex problems are not solved in the country. Academician V. M. Glushkov would say now: with such an economics and economists one can live to the Stone Age.

The scheme of economic quality management during the process of overcoming stagnation. In fig. 1 the $\mathrm{X}$-axis is the time (months) of the economic development process, the $\mathrm{Y}$-axis - the values of the $\mathrm{R}$ criterion of economic failure, $A-B-$ the planned trajectory of changing the economic failure criterion, stages of development $j=1,2, \ldots, n$.

Let us use the following variables for the construction of models: $Z j$ - the factors denoting the state of economics, $U j$-controls, $W j$ - infrastructure of the country. Variables $Z, U, W$ and their components are presented by events and logical variables.

$R$ criterion is calculated at each stage; the contributions of events-factors and controls into 
economic failure are analyzed. Values $Z$ at stages $n$ are determined in the management of the process of economic development. Controls $U, W$ are realized while resources are spent.

The state of economy can be treated as an event of validity (success) with probability $P$, as well as an event of non-validity (failure) with probability $R=1-P$. Below, in order to make manual calculations simpler we use system validity, although the Arbiter software complex uses the non-validity of a system (factor) more often.

The system which controls the process of overcoming economic stagnation includes the following components: objects of management (economy, systems, industries), subjects of management (state officials, specialists, scientists), factors of economic quality, natural management factors (investments, taxes), artificial management factors (loans, R\&D agreements), infrastructure (connections and functions of ministries in the government).

Let us use the following logical model (function) of the success of controlling the process of overcoming economic stagnation:

where:

$Z$ is the model of the validity of the state of economics,

$U$ is the model of the success of controls for overcoming economic stagnation,

$W$ is the model of the success of infrastructure needed for overcoming economic stagnation.

The model of the validity of the state of economy. Let us use the following notation of the factors of the quality of economy:

1) the initial state of economy $A$ is described by the following factors: $Z_{1}$ beg - the number of unemployed, $Z_{2}$ beg - average salary, $Z_{3}$ beg - standard of living, $Z_{4 \text { beg }}-$ rates of industrial growth;

2) the final state of economics $B$ is described by the values of factors: $Z_{1 \text { end }}, Z_{2}$ end,$Z_{3}$ end, $Z_{4}$ end . $Z_{4 \min }$

3) minimum values of factors $Z_{1 \min }, Z_{2} \min , Z_{3 \min }$, $Z_{4 \max }$.

4) maximum values of factors: $Z_{1 \text { max }}, Z_{2 \max }, Z_{3 \max }$,

Let us denote Boolean events-propositions about validity of factors by logical variables $Y_{1}, Y_{2}, Y_{3}, Y_{4}$. Normalized values of variables, taking into account the nature of their monotonicity in relation to the quality of economy, equal:

The value of variables $Y_{1}, Y_{2}, Y_{3}, Y_{4}$ are treated as

$$
\begin{aligned}
& Y_{1}=\left(Z_{1 \text { init }}-Z_{1_{\text {final }}}\right) /\left(Z_{1 \text { init }}-Z_{1 \text { min }}\right) \\
& Y_{2}=\left(Z_{2 \text { final }}-Z_{2 \text { init }}\right) /\left(Z_{2 \text { final }}-Z_{2 \text { min }}\right) \\
& Y_{3}=\left(Z_{3 \text { final }}-Z_{3 \text { init }}\right) /\left(Z_{3 \text { final }}-Z_{3 \text { min }}\right) \\
& Y_{4}=\left(Z_{4 \text { final }}-Z_{4 \text { init }}\right) /\left(Z_{4 \text { кон }}-Z_{4 \text { min }}\right)
\end{aligned}
$$

probabilities of their validity $P_{1}, P_{2}, P_{3}, P_{4}$.

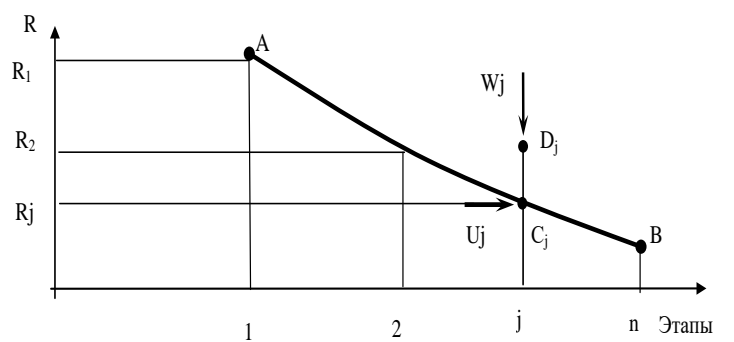

Fig. 1. The scheme of economic development management with the aim of overcoming stagnation

The scenario of economic validity: the event-validity of a system happens due to any single factor, any two factors, or events-validity of all factors. The scenario is written down as a logical function of economic validity at the stage:

$$
Y=Y_{1} \wedge Y_{2} \wedge Y_{3} \wedge Y_{4}
$$

The probabilistic function (criterion) of economic validity at the stage:

$$
P_{Y}=P_{1} P_{2} P_{3} P_{4} \text {. }
$$

The criterion of economic non-validity at the stage:

$$
R y=1-P y \text {. }
$$

Non-validity of an economic factor is the deviation of its value from the set one. Non-validity characterizes a loss of quality. The values of criteria of validity and nonvalidity of economy at any values of probabilities $P_{1}, P_{2}$, $P_{3}, P_{4}$ belong to the interval $\{0,1\}$. During analysis we calculate quantitative contributions of factors $Z_{1}, Z_{2}, Z_{3}$, $Z_{4}$ into the criteria of validity $P_{Y}$ or non-validity $\mathrm{R}_{y}$ of economy. They depend on probabilities $P_{1}, P_{2}, P_{3}, P_{4}$.

The model of the success of controls for overcoming economic stagnation. Natural controls include:

$U_{1}$ - investments,

$U_{2}$-taxes,

$U_{3}$ - involvement of state officials, specialists, scientists and public opinion.

Artificial controls include:

$U_{4}$ - loans,

$U_{5}-\mathrm{R} \& \mathrm{D}$ agreements about the development of the program for overcoming stagnation and analysis of results.

The author does not possess information about the structure of the government and the connections within it , therefore, a single parameter $W_{1}-$ the influence of infrastructure is used.

Let us denote controls $U_{1}, \ldots, U_{5}$ and the influence of infrastructure $W_{1}$ by events and logical variables $Y_{5}, Y_{6}$, $Y_{7}, Y_{8}, Y_{9}, Y_{10}$. Their probabilities $P_{5}, P_{6}, \ldots, P_{10}$ of overcoming stagnation successfully will be assessed by non-numerical, inexact and incomplete expert information [11].

In this case the logical model of the success of controlling the process of overcoming economic 
stagnation, using the model (19) obtained previously at the stage will be written down:

$$
Y=Y_{1} \wedge Y_{2} \wedge Y_{3} \wedge Y_{4} \wedge Y_{5} \wedge Y_{6} \wedge Y_{7} \wedge Y_{8} \wedge Y_{9} \wedge Y_{10}
$$

The probabilistic model of overcoming stagnation successfully by a system at the stage:

$$
\begin{array}{lllllllllllll}
P=P_{1} & P_{2} & P_{3} & P_{4} & P_{5} & P_{6} & P_{7} & P_{8} & P_{9} & P_{10}
\end{array}
$$

The process of overcoming stagnation. Let us describe the process of the management of overcoming stagnation.

At stage 1 the logical model of success $Y$ of the system overcoming stagnation is built:

$$
Y^{1}=Z^{1} \wedge U^{1} \wedge W^{1}
$$

Success criteria $P^{1}$ and failure criteria $R^{1}$, as well as the contributions of components $Z, U$ and $W$ into criteria are calculated. After we select and apply new controls $U$ and $W$ in order to make a transition to stage 2 and obtain new values of factors $\mathrm{Z}$.

At stage 2 we build a new logical model:

$$
Y^{2}=Z^{2} \wedge U^{2} \wedge W^{2}
$$

and calculate success criteria $P^{1}$ and failure criteria $R^{1}$, as well as the contributions of components $Z, U$ and $W$ into the criteria. If the values of criteria $P^{2}$ and $R^{2}$ do not satisfy us, we make a transition to stage 3 , using the above algorithm, etc.

After every stage of analysing the contributions of components of vectors $Y, U$ and $W$ a decision is also made about a partial or complete exclusion of certain artificial controls.

Example. In accordance with the previously introduced notation of events and logical variables let us set the following probabilities of validity of events: $P_{1}=P_{2}=P_{3}=P_{4}=0.8 ; P_{5}=P_{6}=P_{7}=P_{8}=P_{9}=0.9 ; P_{10}=0.7$. In this case the probability of the validity of economic stagnation according to formula (2) $P=0.1693$, and the probability of non-validity of economics stagnation equals: $R=1-P=1-0,1693=0,8307$. It should be pointed out that the calculation of validity (success) of overcoming economic stagnation by arithmetic addition of the probabilities of events or by their averaging would yield an incorrect or even an absurd result. Logical functions have no coefficients and exponents of logical variables. The values of the criteria of validiy and invalidity with any probabilities of factors belong to the interval $\{0,1\}$. The quantitative assessment of significance and contributions of events $Y_{1}, Y_{2}, \ldots, Y_{10}$ into criteria $P$ and $R$ are proportionate to their probabilities. The contribution of non-validity of events-factors into system non-validity for minus and for plus is calculated algorithmically on the P-model of system validity (20 for every event-factor. The contribution for the minus is calculated as the difference of criterion $P$ values with the value $P_{i}$ and the value of criterion $P$ with $P_{i}=0$. The contribution for the plus is calculated as the difference of criterion $P$ value with the value $P_{i}$ and criterion $P$ when $P i=1$.

Based on the value of the system validity criterion and contributions of events-factors controls $U$ and $W$ are used, investments are made, structural changes and innovations are introduced in technology and management, taxes are changed. During the next stage (month) of system development the real changes in the values of system factors are assessed, according to the described technique the new LP-model of system validity is built, analysis is conducted, controls are used, etc.

The students of the four groups of Institute of Business Technologies from St. Petersburg State University of Aerospace Instrumentation experience no difficulties doing such research during laboratory works done on Arbiter и Expa software complexes.

\section{CONCLUSION}

The paper describes mathematical model for managing the quality of condition, development and exit of economic system from the condition of stagnation on the basis of event-driven management of the quality of economics.

\section{REFERENCES}

[1] Aganbegian A. G. The Crisis: A disaster and a chance for Russia. M: Astrel. Harvest, 2009.

[2] Solozhentsev E. D. Artificial intelligence in event-driven management of economics and the state / International Scientific Conference MASR 2020.- SPb.: SUAI. 2020.

[3] Hovanov N., Yadaeva M., Hovanov K. Multicriteria Estimation of Probabilities on the Basis of Expert Non-numerical, Inexact and Incomplete Knowledge / European Journal of Operational Research. 2007. Vol. 195. N 3. P. 857-863.

[4] Solozhentsev E. D. Risk Management Technologies with Logic and Probabilistic Models. Dordrecht, Heidelberg, New York, London: Springer. 2012. 328 p.

[5] Solozhentsev E. D. Management of quality of economics and state "from above" and "from bellow" / Economics and Management. GUAP. 2020. N 3. P. 43-58.

[6] Solozhentsev E. The Management of Socioeconomic Safety. Cambridge Scholars Publishing. 2017. 255 p.

[7] Solozhentsev E. D. The Basics of Event-Related Management of Safety and Qual1ity in Economics / ENVIRONMENT. TECHNOLOGY. RESOURCES. Proc. of 12th Intern. Scientific and Practical Confer. Vol.1, Rezekne Academy of Technologies. 2019. P. 146-153.

[8] Solozhentsev E., Karasev V. (2020) Digital management of structural complex system in economics / Int. J. of Risk Assessment and Management, V. 23, N 1. 2020. P. 54--79.

[9] Solozhentsev E. D. Non-validity and events-propositions in logical-probabilistic models of risk management in socioeconomic systems / Problems of Risk Analysis. 2015, N 6.P. 3043.

[10] Solozhentsev E. D. New problems of event-driven digital state and economic management / Problems of risk analysis. Vol. 12, N 2.2020.

[11] Solozhentsev E. D. Foundation of event-driven management of quality of economics, state and human life. Pb.: Nauka, 2021, 175p. 